\title{
On Capability Indices for Multivariate Autocorrelated Processes
}

\author{
Sueli Aparecida Mingoti \\ Federal University of Minas Gerais (UFMG), Belo Horizonte, MG, Brazil \\ Fernando Luiz Pereira de Oliveira \\ Federal University of Ouro Preto (UFOP), Ouro Preto, MG, Brazil
}

\begin{abstract}
In this paper the effects of the autocorrelation on some multivariate capability indices commonly used for independent processes are discussed and a correction is proposed. Some results are shown for VARMA $(1,1)$ and VAR(1) time series processes under the multivariate normality assumption and the proportion of non-conforming units is calculated for some bivariate VAR(1) models. An extension of Veevers capability index for non-centered processes is also a subject addressed in this paper. An example of application in blast charcoal furnace pig iron process is presented and bootstrap is used to build confidence intervals for its true capability value as well as to evaluate the performance of the capability estimators. Similar as to what is already known for univariate processes the results showed that autocorrelation has a large impact in the multivariate capabilities indices. This paper also shows that some care should be taken when using Niverthi and Dey's capabilities indices since they are very sensitive to any deviations from the process means to the specification means up to a point that a capable process might be considered non-capable.
\end{abstract}

Keywords: Autocorrelated processes, Bootstrap, Multivariate capability indices, Multivariate time series.

\section{Introduction}

Process capability indices are used to quantify the process performance in meeting the required specification limits. Many papers can be found in the literature discussing the capability for independent and autocorrelated normal univariate processes (Koltz and Johnson, 2002; Zhang, 1998). However, most of the processes have their performance evaluated according to multiple quality characteristics which in general are correlated (Mason and Young, 2002). In these situations Multivariate Capability Indices (MCI) are more appropriated. The univariate specification limits are replaced by a specification region and capability indices are generated according to the joint probability distribution of the variables, which in general is taken as the multivariate normal distribution. One of the simplest MCI is the geometric mean of the univariate capability values of the quality characteristics used to evaluate the process performance (Chan et al.,1991). However, this index may not be able to show the true condition of the process performance and it does not take into consideration the possible correlation 
between the variables. Other MCI which depend upon the correlation structure of the variables have been proposed in the literature for independent processes. Wang et al. (2000) compared three indices: Taam et al (1993), Chen (1994) and Shahriari et al. (1995), considering some particular examples. Pearn et al. (2007) presented a study of distributional and inferential properties of the $M C_{P}$ and $M C_{p m}$ multivariate indices proposed by Taam et al. (1993). Niverthi and Dey (2000) extended the univariate $C_{P}$ and $C_{p k}$ indices for the multivariate case. A viability index for multiresponse process was introduced by Veever's (1998) and it is very appealing since it is a function of the univariate capability indices, it is easy to calculate and corrects some of the problems of the geometric mean. Capability measures such as Cheng and Spiring's (1989) and Bernardo and Irony's (1996) were derived under Bayesian framework. More recently Mingoti and Glória (2008) introduced some indices suitable to measure the capability of centered and non-centered independent multivariate processes and compared them with the geometric mean and Niverthi and Dey's (2000). Their indices are extensions of Chen's multivariate capability index (1994) and based on Hayter and Tsui's (1994) multivariate statistical test for the population mean vector.

Although many capability indices are built under the independence assumption it is well known that positive autocorrelation among process data is very common for continuous manufacturing processes such as the production of pig iron or other chemical processes. For univariate processes it is already known that autocorrelation affects the control charts limits as well as the values of the capability indices built under independence assumption (see for example Alwan and Roberts, 1995; Zhang, 1998, among others). In the case of positive correlation among the observations the false alarm proportion of control charts increases and the capability estimate overestimates the true process capability. For multivariate processes it has also been shown that the autocorrelation affects the multivariate control charts and some corrections have been proposed (Kalgonda and Kulkarni, 2004; Jarrett and Pan, 2007). However, little attention has been given to the effects of the autocorrelation on the multivariate capability indices. In this paper we will address this subject and we will present a comparison among some MCI under several autocorrelation settings. An extension of Veevers' index (1998), called Cpkmulti, is also proposed for noncentered processes. For better comprehension the multivariate indices which are part of this study are introduced in section 2; the multivariate time series models are presented in section 3; a theoretical discussion about the autocorrelation effects on the capability values from multivariate processes is presented in section 4 for VAR(1) and $\operatorname{VARMA}(1,1)$ models with the calculation of the proportion of non-conforming process units for some VAR(1) models. An example of application in blast charcoal production of pig iron is shown in section 5 with bootstrap being used to generate confidence intervals for the true capability value of the process and to evaluate the performance of the capability estimators.

\section{Multivariate Capability Indices}

This section presents the multivariate capability indices that will be compared in this paper. In all cases it is assumed that the random vector containing the $p$ quality characteristics of interest, $X=\left(X_{1} X_{2} \ldots X_{p}\right)^{\prime}$, has a $p$-variate normal distribution with mean vector $\mu^{0}=\left(\mu_{1}^{0} \mu_{2}^{0} \ldots \mu_{p}^{0}\right)^{\prime}$, covariance and correlation matrices given by $\Sigma_{p x p}$ and $P_{p x p}$, respectively. 


\section{The Geometric Mean of the Univariate Capability Indices}

Let $X$ be the quality characteristic with normal distribution with parameters $\mu_{i}^{0}$ and $\sigma_{i}$. Let $L S L_{i}$ and $U S L_{i}$ be the lower and upper specification limits respectively. The univariate capability indices $C_{p i}$ and $C_{p k i}$ are defined as (Koltz and Johnson, 1993):

$$
\begin{aligned}
& C_{p_{i}}=C_{p}\left(X_{i}\right)=\frac{U S L_{i}-L S L_{i}}{2 m \sigma_{i}} \\
& C_{p k_{i}}=C_{p k}\left(X_{i}\right)=\min \left\{\frac{U S L_{i}-\mu_{i}^{0}}{m \sigma_{i}} ; \frac{\mu_{i}^{0}-L S L_{i}}{m \sigma_{i}}\right\}
\end{aligned}
$$

These indices quantify the relationship between the process and the manufacturing specification limits at a certain confidence level which depends upon the choice of the constant $m$. The value of this constant comes from the univariate standard normal distribution. A common value is $m=3$ which corresponds to a $99.73 \%$ confidence level. Some references values, such as 1.33 or 2, are used to classify the process as being capable or not. A simple extension (Chan et al.,1991) of the indices defined in (1) to the multivariate case is the geometric mean of the $C_{p i}$ and $C_{p k i}$ values obtained for each quality characteristic $X, i=1,2, \ldots, p$, as given in Equations 2,3. However, this procedure does not take into consideration the correlation that might exist among the variables.

$$
\begin{aligned}
& C_{\text {pgeom }}=\left(\prod_{i=1}^{p} C_{p}\left(X_{i}\right)\right)^{1 / p} \\
& C_{\text {pkgeom }}=\left(\prod_{i=1}^{p} C_{p k}\left(X_{i}\right)\right)^{1 / p}
\end{aligned}
$$

The $C_{p k g e o m}$ is not always defined. As a simple example take the case where $p=2$ where one $C_{p k}\left(x_{i}\right)$ is negative and the other positive. Although the geometric mean is simple to calculate it may not show the true non-capability of the process since high capability values of some variables can compensate small capability values of other variables. As an example if one of the variables has $C_{p k}\left(X_{i}\right)$ equals 3 and the other equals 0.75 the geometric mean in (3) will be equal to 1.5 indicating that the process is capable.

\section{Multiple-Response Viability Veevers' Index}

Let $U S L=\left(U S L_{1} U S L_{2} \ldots U S L_{p}\right)^{\prime}$ ' and $L S L=\left(L S L_{1} L S L_{2} \ldots L S L_{p}\right)^{\prime}$ 'be the upper and lower specification vectors, $L S L_{i}$ and $U S L_{i}$ as defined before, $i=1,2, \ldots p$. Let $C_{p}\left(X_{i}\right)$ the univariate capability index of $X_{i}, i=1,2, \ldots, p$, defined as in (1). According to Veevers (1998) the multivariate capability index, $\mathrm{C}_{p \text { Veevers }}$, is defined by (4) if at least one $C_{p}\left(X_{i}\right)$ is less than 1 and it is defined as (5) otherwise, $i=1,2, \ldots, p$.

$$
C_{p \text { Veevers }}=\prod_{i=1}^{p} C_{p}\left(X_{i}\right)^{I i} \text { where } I_{i}=\left\{\begin{array}{l}
0, \text { if } C_{p}\left(X_{i}\right) \geq 1 \\
1, \text { if } C_{p}\left(X_{i}\right)<1
\end{array}\right.
$$




$$
C_{p \text { Veevers }}=\frac{\prod_{i=1}^{p} C_{p}\left(X_{i}\right)}{\prod_{i=1}^{p} C_{p}\left(X_{i}\right)-\prod_{i=1}^{p}\left[C_{p}\left(X_{i}\right)-1\right]}
$$

$p$ It is interesting to notice that $\mathrm{C}_{p \text { Veevers }}$ value in (4) is always smaller than $\prod_{i=1}^{p} C_{p}\left(X_{i}\right)$. Similarly the correction used in the denominator of (5) makes the value of $\mathrm{C}_{\text {pVevers }}$ be smaller than $\prod_{i=1}^{p} C_{p}\left(X_{i}\right)$ when all capability indices are larger than 1 . The Veevers' capability index corrects some biases of the geometric mean. As an illustration if $p=2$, one $C_{P}\left(X_{i}\right)$ is 3 and the other is 0.75 Veevers' capability index will be equal to 0.75 different from the value 1.5 given by the geometric mean.

\section{An Extension of Multiple-Response Viability Veevers' Index for Non-Centered Process}

The indices in (4) and (5) are not sensite to the differences between the specification and process means. Following Veevers' approach in this paper we propose the $C p k m u l t i$ index which is sensitive to these possible differences. Let $C_{p k}\left(X_{i}\right)$ be defined as in (1). The proposed new index is defined as in (6) if at least one $C_{p k}\left(X_{i}\right)$ is less than 1 and it is defined as (7) otherwise, $i=1,2, \ldots, p$.

$C_{p k m u l t i}=\prod_{i=1}^{p} C_{p k}\left(X_{i}\right)^{I_{i}} \quad$ where $I_{i}=\left\{\begin{array}{lll}0, & \text { if } & C_{p k}\left(X_{i}\right) \geq 1 \\ 1, & \text { if } & C_{p k}\left(X_{i}\right)<1\end{array}\right.$

$C_{p k m u l t i}=\frac{\prod_{i=1}^{p} C_{p k}\left(X_{i}\right)}{\prod_{i=1}^{p} C_{p k}\left(X_{i}\right)-\prod_{i=1}^{p}\left[C_{p k}\left(X_{i}\right)-1\right]}$

$\stackrel{p}{\prod} C_{p k}\left(X_{i}\right) C_{p k m u l t i}$ is defined in such way that its value is always smaller than

\section{Niverthi and Dey's Multivariate Process Capability Indices}

Niverthi and Dey (2000) proposed an extension of the univariate $C_{p}, C_{p k}$ (Equations 1,2) for the multivariate case as follows. Let the specification vectors USL and $L S L$ be defined as before. Niverthi and Dey's multivariate versions of univariate $C_{p}$ and $C_{p k}$ are linear combinations of the upper and lower specification limits of all variables and are defined as (8) and (9).

$$
\begin{aligned}
& C_{p N D}=\frac{1}{2 m} \Sigma^{-1 / 2}(U S L-L S L) \\
& C p k N D=\min \left[\left(\frac{1}{m} \Sigma^{-1 / 2}\left(U S L-\mu^{0}\right) ;\left(\frac{1}{m} \Sigma^{-1 / 2}\left(\mu^{0}-L S L\right)\right]\right.\right.
\end{aligned}
$$

In this case a capability value is generated for each quality characteristic. As before the choice of the constant $m$ is based on the univariate standard normal distribution. Niverthi and Dey (2000) used $m=3$ which corresponds to a confidence 
level of $99.73 \%$ or a significance level of $\alpha=0.0027$. The difficulty in using $C_{p N D}$ and $C_{p k N D}$ to classify the process as being capable or not comes from the fact that there are no reference values to which these vectors could be compare to. One possibility is to employ the usual univariate 1.33 or 2 reference values for each variable separately. Another is to define the global capability process estimate as the minimum value of the vectors $C_{p N D}$ and $C_{p k N D}$ respectively, as suggested in Mingoti and Glória's (2008).

\section{Mingoti and Glória's Multivariate Capability Indices}

Mingoti and Glória (2008) proposed two multivariate indices called $\mathrm{C}_{p}^{m}$ and $\mathrm{C}_{p k}^{m}$. They are extensions of Chen's multivariate capability index (1994) and based in Hayter and Tsui's (1994) multivariate statistical test for vector mean of normal populations. Let $L S L_{i}$ and $U S L_{i}$ be the lower and upper specification limits for the quality characteristic $X_{i}$. Define $r_{i}^{l}=\mu_{i}^{s}-\mathrm{LSL}_{i}$ and $r_{i}^{2}=\mathrm{USL}_{i}-\mu_{i}^{s}$, where $\mu_{i}^{s}$ is the nominal (specification) mean of $\mathrm{X}_{i}, i=1,2, \ldots, p$. Mingoti and Glória's multivariate capability index $\mathrm{C}_{p}^{m}$ is then defined as

$$
C_{p}^{m}=\min \left\{C_{p i}^{m}, i=1,2, \ldots, p\right\}
$$

where

$$
C_{p i}^{m}=\left[\frac{U S L_{i}-L S L_{i}}{2 \sigma_{i} C_{r \alpha}}\right]=\left[\frac{r_{i}^{2}+r_{i}^{1}}{2 \sigma_{i} C_{r \alpha}}\right], i=1,2, \ldots, p
$$

When $\mathrm{C}_{p}^{m}$ is larger or equal to 1 the process will be considered capable with a certain confidence level $(1-\alpha) 100 \%$. The $C_{r \alpha}$ value is obtained by using simulation of samples from a $p$-variate normal distribution with zero mean vector and covariance matrix $P_{p x p}$. In practice the matrix $P_{p x p}$ is estimated by the sample correlation matrix $R_{p x p}$ of $X$. The steps of the simulation algorithm (Hayter and Tsui, 1994) used to obtain the constant $C_{r \alpha}$ is given as follows.

Step 1. Generate a large number $N$ of vectors of observations from a $p$-variate normal distribution with zero mean vector and covariance matrix $P_{p x p}$. The generated vectors are denoted by $Z^{1}, Z^{2}, \ldots, Z^{N}$.

Step 2. Calculate the statistics $M$ for each of the generated vectors $Z^{j}=\left(Z_{l}^{j}\right.$, $\left.Z_{2}^{j}, \ldots, Z_{p}^{j}\right)$,

from step 1 , i.e, for the every $j=1,2, \ldots, N$, calculate the value of the statistics $M^{j}=\max \left\{\left|Z_{i}^{j}\right|, i=1,2, \ldots, p\right\}$.

Step 3. From the empirical distribution of $M$ obtained from the sample $\left(M^{1}\right.$, $\left.M^{2}, \ldots, M^{N}\right)$ find the value corresponding to the percentil of order $(1-\alpha)$ and use this value as the critical constant $C_{r \alpha}, 0<\alpha<1$.

This algorithm was also used by Kalgonda and Kulkarni (2004) in control charts for autocorrelated multivariate normal processes. Hayter and Tsui (1994) 
suggested that a total of $N=100000$ simulations should be performed in order to obtain the value of $C_{r \alpha}$ with high precision.

The $\mathrm{C}_{p}^{m}$ defined in (10) is not sensitive to changes in the process vector mean and need to be modified. A more suitable multivariate coefficient $\mathrm{C}_{p k}^{m}$ is defined by Mingoti and Glórias's (2008). For each variable $i, i=1,2, \ldots, p$ let $\mathrm{C}_{p k i}^{p k}$ be defined as

$C_{p k i}^{m}=\min \left(\frac{\mu_{i}^{0}-L S L_{i}}{C_{R \alpha} \sigma_{i}} ; \frac{U S L_{i}-\mu_{i}^{0}}{C_{R \alpha} \sigma_{i}}\right)$

The $\mathrm{C}_{p k}^{m}$ Mingoti and Glória's capability index is defined as

$C_{p k}^{m}=\min \left\{C_{p k i}^{m}, i=1,2, \ldots, p\right\}$

where $\mathrm{LSL}_{i}$ and $\mathrm{USL}_{i}$ are defined as before and $\mu_{i}^{0}$ and $\sigma_{I}$ are the process mean and standard deviation of the variable $\mathrm{X}_{i}$, respectively. Considering that $L S L_{i}=\mu_{i}^{s}-r_{i}^{l}$ and $U S L_{i}=\mu_{i}^{s}+r_{i}^{2}$, where $\mu_{i}^{s}$ is the specification mean of $X_{i}$, the equation (12) reduces to

$C_{p k i}^{m}=\min \left\{\left(\frac{\left.\mu_{i}^{0}-\mu_{i}^{s}+r_{i}^{1}\right)}{C_{R \alpha} \sigma_{i}} ; \frac{\left(\mu_{i}^{s}-\mu_{i}^{0}+r_{i}^{2}\right)}{C_{R \alpha} \sigma_{i}}\right)\right\}$

and therefore $\mathrm{C}_{p k}^{m}$ takes into account possible deviations between the process and the nominal means values. The $\mathrm{C}_{p k}^{m}$ coefficient defined in (13) is equal to the value obtained by Equation 10 when the process is centered in the specification mean vector.

Mingoti and Glória's indices quantify the global capability as well as the capability of the process for each quality characteristic separately. Different from Niverthi and Dey's the correlation structure of the quality characteristics is represented by the constant $C_{r \alpha}$ and not by an inverse square root of the covariance matrix.

\section{Autocorrelated Multivariate Processes}

Although many statistical models are proposed considering independence among the data autocorrelation is very common. In these situations times series models are used to describe the relationship of the series of observations. As pointed out by Kalgonda and Kulkarni (2004) the presence of positive autocorrelation affects the performance of control charts since the Average Run Length (ARL) is much shorter than the expected when the process is under control. We will show that the autocorrelation affects the multivariate capability indices as well.

\section{Time Series Models}

Multivariate time series models (Lutkepohl, 2005) can be used to describe the pattern of autocorrelated multivariate processes. For each time $t$, let $X_{t}=\left(X_{t 1} X_{t 2} \cdots\right.$ $X_{t p}$ )' be a random vector with $p$-variate normal distribution. The VARMA $(1,1)$ model is defined as

$$
X_{t}=\mu_{t}+\Phi\left(X_{t-1}\right)-\Theta\left(\varepsilon_{t-1}\right)+\varepsilon_{t}
$$


where $\mu_{t}=\left(\mu_{t 1} \mu_{t 2} \ldots \mu_{t p}\right)^{\prime}$ is the mean vector of the process at time $t, \varepsilon_{t}=\left(\varepsilon_{t 1} \varepsilon_{t 2} \ldots \varepsilon_{t p}\right)^{\prime}$ is the vector of $p$-variate independent normal random variables with zero mean and covariance matrix $\Sigma_{p x p}, \Phi_{p x p}$ and $\Theta_{p x p}$ are $p x p$ matrices containing the autoregressive and moving average parameters. To be stationary the square roots of the matrix $\Phi_{p x p}$ have to be inside the unit circle or equivalently the eigenvalues of $\Phi_{p x p}$ have to be smaller than 1 . Let $\Gamma(t, t+h)$ be the cross-covariance matrix between $X_{t}^{p x p}$ and $X_{t+h}$ its $(1, \mathrm{k})$ th element given as (16).

$$
\gamma_{l k}(h)=E\left\{\left(X_{t l}-\mu_{t l}\right)\left(X_{t+h k}-\mu_{t+h k}\right)\right\}
$$

Due to the stationarity assumption $\mu_{t}$ is constant for each $t,\left(\mu_{t}=\mu\right)$, and $\Gamma(t, t+h)$ is a function of lag $h$ only and can be denoted as $\Gamma(h)$. The cross-correlation matrix $\rho(h)$ at lag $h$ is given by

$$
\rho(h)=V^{-1 / 2} \Gamma(h) V^{-1 / 2}
$$

where $V=\operatorname{diag}\left(\gamma_{11}(0), \gamma_{22}(0), \ldots, \gamma_{p p}(0)\right)$. It can be shown that for VARMA $(1,1)$ the cross-covariance at lag 0 , when the matrices $\Sigma_{p x p}, \Phi_{p x p}$ and $\Theta_{p x p}$ are given, is obtained by solving the Equations 18 and then, from this, $\rho(0)$.

$$
\Gamma(0)=\Phi \Gamma(0) \Phi^{\prime}+\Theta \sum \Theta^{\prime}-\Phi \sum \Theta^{\prime}-\Theta \sum \Phi^{\prime}+\Sigma
$$

When the matrix $\Theta_{p x p}$ is null (15) turns into a first-order autoregressive model VAR(1) which was discussed by Kalgonda and Kulkarni (2004) and Kramer and Schmid (1997). In this case (18) reduces to $Г(0)=\Phi Г(0) \Phi^{\prime}+\Sigma$. are given by

As an illustration for $p=2$ the VAR(1) equations of the time series model

$$
\begin{aligned}
& X_{t 1}=\mu_{t 1}+\phi_{11} X_{t-1,1}+\phi_{12} X_{t-1,2}+\varepsilon_{t 1} \\
& X_{t 2}=\mu_{t 2}+\phi_{22} X_{t-1,2}+\phi_{21} X_{t-1,1}+\varepsilon_{t 2}
\end{aligned}
$$

The cross terms $\phi_{12}$ and $\phi_{21}$ represent the linear dependence between $X_{t 1}$ and $X_{t-1,2}$ and $X_{t 2}$ and $X_{t-1,1}$, respectively. When both matrices $\Phi_{p x p}$ and $\Theta_{p x p}$ are null the model in (15) reduces to $X_{t}=\mu_{t}+\varepsilon_{t}$. In this situation the observations of the process are independent and $\Sigma_{p x p}$ is the covariance matrix of the random vector $X_{t}$. When one of the matrices $\Phi_{p x p}$ and $\Theta_{p x p}$ are not null the observations of the process are autocorrelated and the covariance structure of $X_{t}$ is affected. In all cases, for each $t$, the random vector $X_{t}$ will have a $p$-variate normal distribution with mean vector $\mu$ and covariance matrix $\Gamma(0)$.

Kalgonda and Kulkarni (2004) proposed a procedure to implement the autocorrelation information in Hotelling $T^{2}$ (1947) and Hayter and Tsui (1994) statistical tests used in multivariate quality control for monitoring the process mean vector. Only first-order autoregressive time series models (VAR(1)) with $p=2$ quality characteristics were considered by the authors. In this paper we will discuss the effects of the autocorrelation in the capability indices described previously when data are generated from $\operatorname{VAR}(1)$, for $p=2$ and 3, and from $\operatorname{VARMA}(1,1)$ models for $p=2$.

\section{Correcting the Capability Indices for Multivariate Autocorrelated Processes}

As shown before the autocorrelation affects the covariance matrix of the process. As a consequence the multivariate indices described before are also affected. An 
alternative of correcting the values of those indices is to use the variance and covariance information contained in $\Gamma(0)$ matrix instead of $\Sigma_{p x p}$ in order to calculate the capability indices. This is the approach proposed in this paper and that will be discussed in the next section for $\operatorname{VAR}(1)$ and $\operatorname{VARMA}(1,1)$ processes.

\section{Comparing Capability Indices - Autocorrelated Processes}

To understand how the autocorrelation affects the process capability values a study was performed under several settings described in Tables 1-3. The models in Table 1 are $\operatorname{VAR}(1)$ for $p=2$ and $p=3$, and $\operatorname{VARMA}(1,1)$ for $p=2$. Tables 2,3 show the specification and the process limits for all models of Table 1. For each case and model the capability indices described were calculated based on both matrices $\Sigma_{p x p}$ and $\Gamma(0)$ (Tables 4-6). The ratio between the capability results obtained in both situations are presented. For Niverthi and Dey's indices the global capability process estimate was defined as the minimum value of the vectors $C_{p N D}$ and $C_{p k N D}$ respectively, as suggested in Mingoti and Glória's (2008).

The results based on $\Sigma_{p x p}$ matrix ignore the autocorrelation among the observations. On the contrary, the results based on $\Gamma(0)$ take into account the autocorrelation. As one can see there is a huge difference between the numerical values of the capability indices calculated under independent and autocorrelated data. In all cases the capability values based on the matrix $\Gamma(0)$ are lower (in absolute value) than the values based on $\Sigma_{p x p}$ and in general the differences are larger for Niverthi and Dey's. When the matrix $\Gamma(0)$ is used, all the capability indices, except the geometric mean, were able to recognize the processes which were not capable. The same was not true when the capability is calculated using the matrix $\Sigma_{p x p}$ (Table 4, cases 3 and 4). The ratio between the capability results calculated with $\Sigma_{p x p}$ and $\Gamma(0)$ show that the difference was much larger for $\operatorname{VAR}(1)$ with $p=2$, than for $\operatorname{VAR}(1)$ with $p=3$ and $\operatorname{VARMA}(1,1)$. Niverthi and Dey's had the tendency to result in smaller capability values when compared to the other indices.

As an illustration in Figure 1a-d, the specification and the process confidence regions (99.73\%) are shown for VAR(1) model defined according to Table 2, $p=2$. The probability of non-conforming units with respect to the specification limits are also presented. Comparing these plots with the capability results of Table 4 we can see that the capability indices calculated by using matrix $\Sigma_{p x p}$ were completely inappropriate for case 3 (except Niverthi and Dey's). The non-capability of case 4 and the possible non-capability of case 3 are clearly signaled when matrix $\Gamma(0)$ is used to quantify the capability. It is important to notice that the numerical values of the multivariate indices based on $\Gamma(0)$ discussed in this paper reflect well the condition of the process in terms of the proportion of non-conforming ( $p$ ). For case 1, $p$ is approximately zero and all the multivariate capability indices resulted in numerical values larger or equal 1.33; for case 2, p is 0.1532 (153200 ppm) and the multivariate capability indices were lower than 0.5 except for the geometric mean which was equal to 0.97 ; for case 4 a non-centered process, clearly non-capable in the second variable and with a value of p equals to $0.1151(115100 \mathrm{ppm})$ the multivariate capability indices of $C_{p k}$ type were approximately equal to 0.4 (except the geometric mean that was equal to 0.89 ). For case 3 which represents a situation where the specification limits for the second 


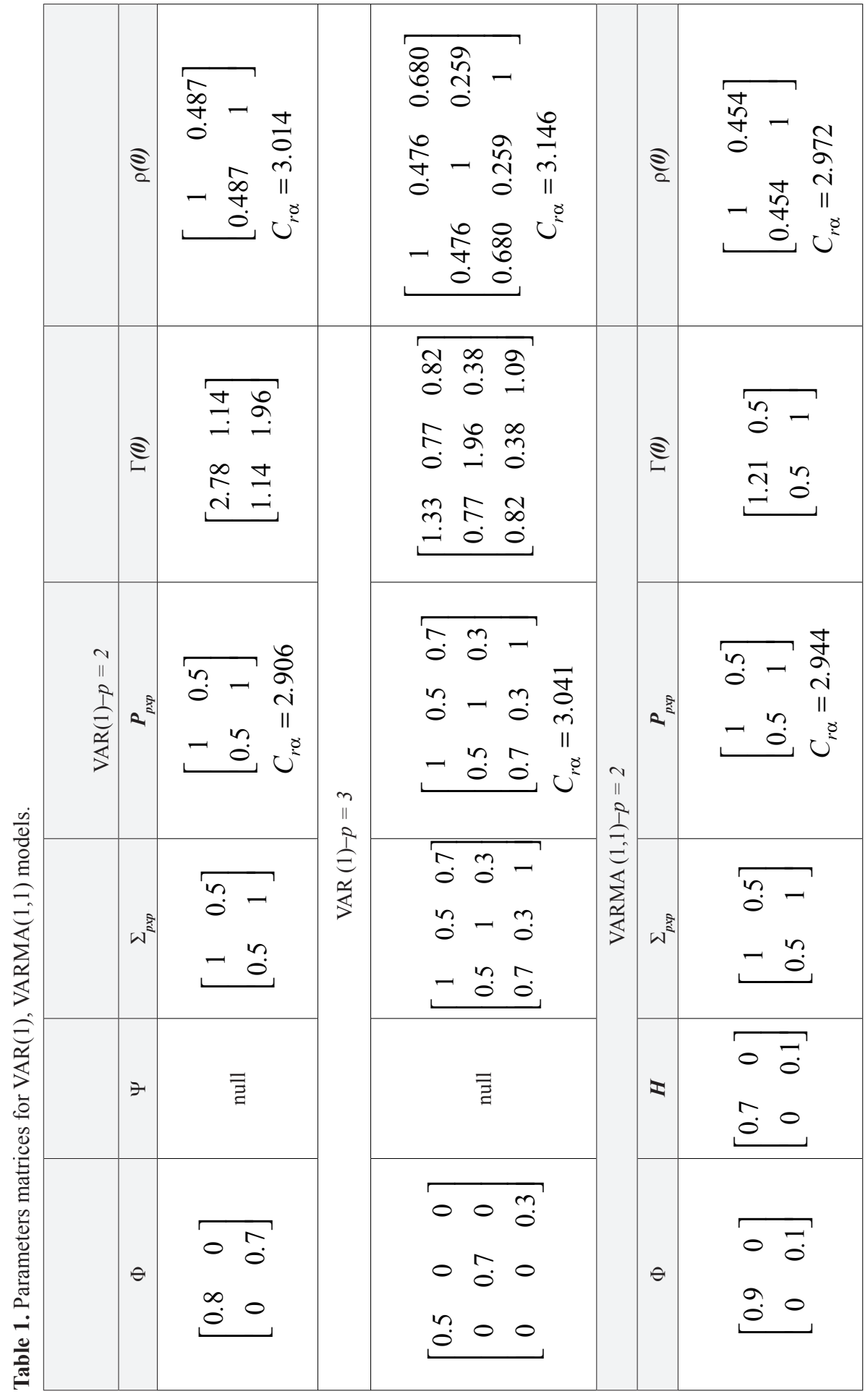


Table 2. Specification and process limits $-\mathrm{p}=2$.

\begin{tabular}{|c|c|c|c|c|c|}
\hline Cases & $\begin{array}{c}\text { Specification } \\
\text { limits } \\
\text { variable } 1\end{array}$ & $\begin{array}{c}\text { Specification } \\
\text { limits } \\
\text { variable } 2\end{array}$ & $\begin{array}{c}\text { Process limits } \\
\text { variable } 1\end{array}$ & $\begin{array}{l}\text { Process limits } \\
\text { variable } 2\end{array}$ & $\begin{array}{l}\text { Process } \\
\text { condition }\end{array}$ \\
\hline & & $\operatorname{VAR}(1)$ & & & \\
\hline 1 & {$\left[\begin{array}{lll}30 & 40 & 50\end{array}\right]$} & {$\left[\begin{array}{llll}21.6 & 30 & 38.4\end{array}\right]$} & {$\left[\begin{array}{lll}35 & 40 & 45\end{array}\right]$} & {$\left[\begin{array}{llll}25.8 & 30 & 34.2\end{array}\right]$} & centered-capable \\
\hline 2 & {$\left[\begin{array}{lll}30 & 40 & 50\end{array}\right]$} & {$\left[\begin{array}{llll}28.0 & 30 & 32.0\end{array}\right]$} & {$\left[\begin{array}{lll}35 & 40 & 45\end{array}\right]$} & {$\left[\begin{array}{llll}25 & 5.8 & 30 & 34.2\end{array}\right]$} & centered-noncapable \\
\hline 3 & {$\left[\begin{array}{lll}30 & 40 & 50\end{array}\right]$} & {$\left[\begin{array}{llll}25.8 & 30 & 34.2\end{array}\right]$} & {$\left[\begin{array}{lll}35 & 40 & 45\end{array}\right]$} & {$\left[\begin{array}{llll}25 & 5.8 & 30 & 34.2\end{array}\right]$} & centered-capable $(*)$ \\
\hline \multirow[t]{2}{*}{4} & {$\left[\begin{array}{lll}30 & 40 & 50\end{array}\right]$} & {$\left[\begin{array}{llll}2 & 1.6 & 30 & 38.4\end{array}\right]$} & {$\left[\begin{array}{lll}43 & 48 & 53\end{array}\right]$} & [ $\left.\begin{array}{llll}25.8 & 30 & 34.2\end{array}\right]$ & $\begin{array}{c}\text { non-centered- } \\
\text { noncapable }\end{array}$ \\
\hline & & $\operatorname{VARMA}(1,1)$ & & & \\
\hline 5 & {$\left[\begin{array}{llll}33.3 & 40 & 46.6\end{array}\right]$} & {$\left[\begin{array}{llll}24 & 30 & 36\end{array}\right]$} & {$\left[\begin{array}{llll}36.7 & 40 & 43.3\end{array}\right]$} & {$\left[\begin{array}{lll}27 & 30 & 33\end{array}\right]$} & centered-capable \\
\hline 6 & {$\left[\begin{array}{llll}33.3 & 40 & 46.6\end{array}\right]$} & {$\left[\begin{array}{llll}29 & 30 & 31\end{array}\right]$} & {$\left[\begin{array}{lll}36.7 & 40 & 43.3\end{array}\right]$} & {$\left[\begin{array}{lll}27 & 30 & 33\end{array}\right]$} & centered-noncapable \\
\hline 7 & [33.3 40466.6$]$ & {$\left[\begin{array}{lll}24 & 30 & 36\end{array}\right]$} & [40.7 44 47.3] & {$\left[\begin{array}{lll}31 & 34 & 37\end{array}\right]$} & $\begin{array}{l}\text { noncentered- } \\
\text { noncapable }\end{array}$ \\
\hline
\end{tabular}

*This process is barely capable in the second variable.

Table 3. Specification and process limits $-\operatorname{VAR}(1)-\mathrm{p}=3$.

\begin{tabular}{|c|c|c|c|}
\hline Parameters & Case 8 & Case 9 & Case 10 \\
\hline Specification limits - variable 1 & [33.0 4047.0$]$ & [33.0 4047.0$]$ & [33.0 4047.0$]$ \\
\hline Specification limits - variable 2 & {$\left[\begin{array}{llll}21.6 & 30 & 38.4\end{array}\right]$} & {$\left[\begin{array}{lllllll}2 & 1.6 & 30 & 38.4\end{array}\right]$} & {$\left[\begin{array}{llllll}21.6 & 30 & 38.4\end{array}\right]$} \\
\hline Specification limits - variable 3 & {$\left[\begin{array}{llll}13.6 & 20 & 26.4\end{array}\right]$} & {$\left[\begin{array}{llll}13.6 & 20 & 26.4\end{array}\right]$} & {$\left[\begin{array}{llll}13.6 & 20 & 26.4\end{array}\right]$} \\
\hline Process limits - variable 1 & [36.5 $\left.40 \begin{array}{lll}36 & 43.5\end{array}\right]$ & [42.5 46 49.5] & [42.5 46 49.5] \\
\hline Process limits - variable 2 & {$\left[\begin{array}{llll}25 & 5.7 & 30 & 34.3\end{array}\right]$} & {$\left[\begin{array}{llllll}2 & 6.8 & 3 & 3 & 35.2\end{array}\right]$} & {$\left[\begin{array}{llll}3 & 0.8 & 35 & 39.2\end{array}\right]$} \\
\hline Process limits - variable 3 & {$\left[\begin{array}{llll}16.8 & 20 & 23.2\end{array}\right]$} & {$\left[\begin{array}{llll}16.8 & 20 & 23.2\end{array}\right]$} & {$\left[\begin{array}{llll}20.8 & 24 & 27.2\end{array}\right]$} \\
\hline Process condition & centered-capable & $\begin{array}{c}\text { noncentered- } \\
\text { noncapable }\end{array}$ & noncentered-noncapable \\
\hline
\end{tabular}

variable are equal to the process limits, the value of $\mathrm{p}$ is 0.0027 (2700 ppm) and the multivariate capability indices were lower but close to 1, except Niverthi and Dey's which resulted the value 0.49 .

From the results in Tables 4-6 it is clear that Niverthi and Dey's penalizes the processes more than the other indices even when the probability of non-conforming process units is small (see case 3 whose proportion of non-conforming process units according to the specification limits is 0.0027 ). Due to this tendency it is possible that a capable process will be considered non-capable by Niverthi and Dey's indices (Mingoti and Glória, 2008). On the other hand, Mingoti and Glória's and Veevers' were more stable and produced more suitable information about the true capability (capability values close to 1 for case 3 ).

\section{Example of Application}

When data is collected from a multivariate normal process with the purpose of estimating its capability the first step is to verify if the autocorrelation is present in the data and then to identify the appropriate time series model that is generating 
Case $1-p=0$

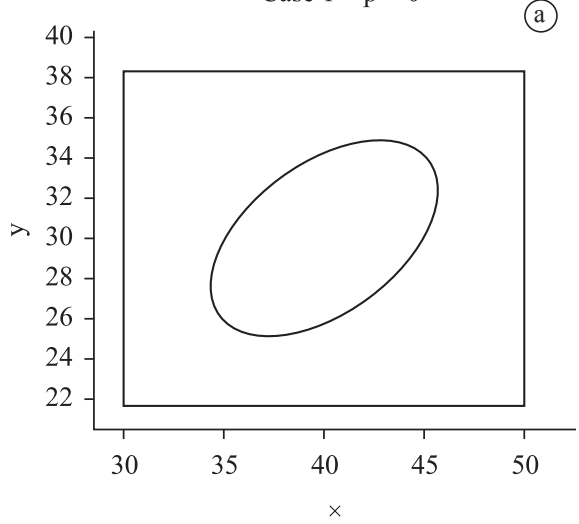

Case $3-p=0.0027$

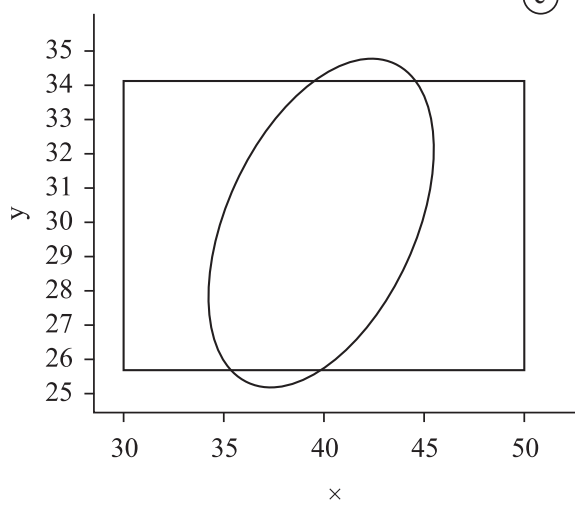

Case $2-\mathrm{p}=0.1532$

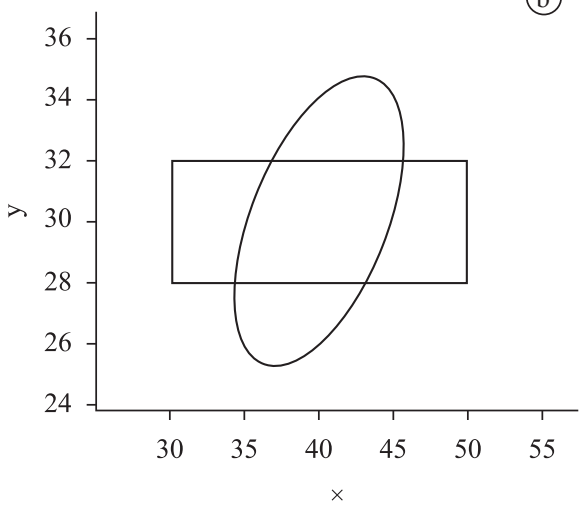

Case $4-\mathrm{p}=0.1151$

(d)

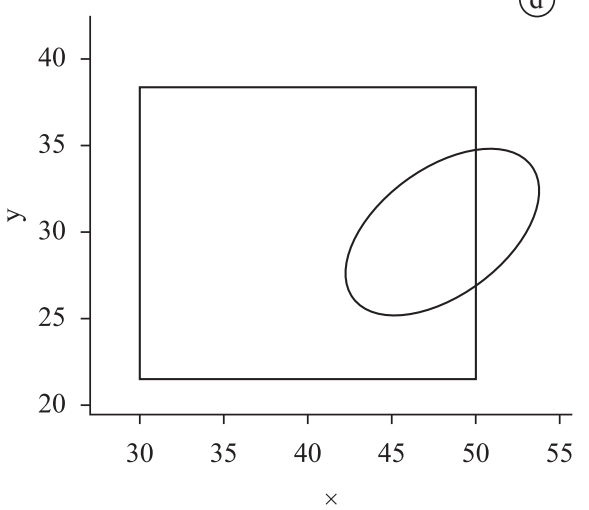

Figure 1. Elipses $(99.73 \%)$ and the specification region - Var(1), bivariate, $p=$ probability of non-conforming units according to the specification limits.

the observations. After the parameters of the model are estimated the values of any capability index presented in this paper can be calculated since the matrices $\Phi, \Sigma_{p x p}$ and $\Gamma(0)$ are estimated by maximum likelihood or other methods (Lutkepohl, 2005). As an illustration we will consider data from a blast charcoal furnace of pig iron production. Two variables were used for this example: $X_{1}$, the air flow measured inside the furnace and $X_{2}$, the air pressure measured at the bottom of the furnace. The specification vectors are $U S L=(21.826 .56)^{\prime}, L S L=(20.445 .5)^{\prime}$ and $\mu^{s}=(21.13 ; 6.03)$. A total of $n=360$ observations were taken in a regular run when the process was under control (every observation was taken at every second). Figure 2 shows the series of observations from both variables and Figure 3 shows the respective partial autocorrelation functions. A VAR(1) model was indicated by the plots since for each variable an autoregressive model was suggested. The estimated parameters for the complete VAR(1) model are shown in (20). Since the cross-parameters estimates were close to zero the VAR(1) model was then adjusted without the cross parameters given the estimates shown in (21) and the residual analysis has shown that it was a well adjusted model (results not shown). 
Table 4. Capability indices results $-\operatorname{VAR}(1)-p=2$.

\begin{tabular}{|c|c|c|c|c|c|c|c|c|c|c|c|c|}
\hline $\begin{array}{c}\text { Capability } \\
\text { indices }\end{array}$ & \multicolumn{4}{|c|}{$\begin{array}{c}\text { By matrix } \Sigma \\
\text { cases }\end{array}$} & \multicolumn{4}{c|}{$\begin{array}{c}\text { By matrix } \Gamma(0) \\
\text { cases }\end{array}$} & \multicolumn{4}{c|}{$\begin{array}{c}\text { Ratio between } \\
\text { Indices }\end{array}$} \\
\hline & 1 & 2 & 3 & 4 & 1 & 2 & 3 & 4 & 1 & 2 & 3 & 4 \\
\hline CP - variable 1 & 3.33 & 3.33 & 3.33 & 3.33 & 2.00 & 2.00 & 2.00 & 2.00 & 1.66 & 1.66 & 1.66 & 1.66 \\
\hline CP - variable 2 & 2.80 & 0.67 & 1.40 & 2.80 & 2.00 & 0.48 & 0.99 & 2.00 & 1.40 & 1.39 & 1.41 & 1.40 \\
\hline CPk - variable 1 & 3.33 & 3.33 & 3.33 & 0.67 & 2.00 & 2.00 & 2.00 & 0.40 & 1.66 & 1.66 & 1.66 & 1.67 \\
\hline CPk - variable 2 & 2.80 & 0.67 & 1.40 & 2.80 & 2.00 & 0.48 & 0.99 & 2.00 & 1.40 & 1.39 & 1.41 & 1.40 \\
\hline CP (Veevers) & 1.82 & 0.67 & 1.25 & 1.82 & 1.33 & 0.48 & 0.99 & 1.33 & 1.36 & 1.39 & 1.26 & 1.36 \\
\hline CPk (Veevers) & 1.82 & 0.67 & 1.25 & 0.67 & 1.33 & 0.48 & 0.99 & 0.40 & 1.36 & 1.39 & 1.26 & 1.67 \\
\hline CP (geometric) & 3.05 & 1.49 & 2.16 & 3.05 & 2.00 & 0.97 & 1.41 & 2.00 & 1.52 & 1.53 & 1.53 & 1.52 \\
\hline CPk (geometric) & 3.05 & 1.49 & 2.16 & 1.37 & 2.00 & 0.97 & 1.41 & 0.89 & 1.52 & 1.53 & 1.53 & 1.53 \\
\hline $\begin{array}{c}\text { CP } \\
\text { (Niverthi-Dey) }\end{array}$ & 2.13 & -0.25 & 0.57 & 2.13 & 1.60 & -0.09 & 0.49 & 1.60 & 1.33 & 2.77 & 1.16 & 1.33 \\
\hline $\begin{array}{c}\text { CPk } \\
\text { (Niverti-Dey) }\end{array}$ & 2.13 & -0.25 & 0.57 & -0.09 & 1.60 & -0.09 & 0.49 & -0.08 & 1.33 & 2.77 & 1.16 & 1.12 \\
\hline $\begin{array}{c}\text { Cpm } \\
\text { (Mingoti-Glória) }\end{array}$ & 2.89 & 0.69 & 1.45 & 2.89 & 1.99 & 0.47 & 0.95 & 1.99 & 1.45 & 1.46 & 1.52 & 1.45 \\
\hline $\begin{array}{c}\text { Cpkm } \\
\text { (Mingoti-Glória) }\end{array}$ & 2.89 & 0.69 & 1.45 & 0.69 & 1.99 & 0.47 & 0.95 & 0.39 & 1.45 & 1.46 & 1.52 & 1.76 \\
\hline
\end{tabular}

Table 5. Capability indices results- VAR (1) $-\mathrm{p}=3$.

\begin{tabular}{|c|c|c|c|c|c|c|c|c|c|}
\hline \multirow[t]{2}{*}{ Capability index } & \multicolumn{3}{|c|}{$\begin{array}{l}\text { By matrix } \Sigma \\
\text { cases }\end{array}$} & \multicolumn{3}{|c|}{$\begin{array}{c}\text { By matrix } \Gamma(0) \\
\text { cases }\end{array}$} & \multicolumn{3}{|c|}{$\begin{array}{c}\text { Ratio } \\
\text { between indices }\end{array}$} \\
\hline & 8 & 9 & 10 & 8 & 9 & 10 & 8 & 9 & 10 \\
\hline $\mathrm{CP}$ - variable 1 & 2.33 & 2.33 & 2.33 & 2.02 & 2.02 & 2.02 & 1.15 & 1.15 & 1.15 \\
\hline $\mathrm{CP}$ - variable 2 & 2.80 & 2.80 & 2.80 & 2.00 & 2.00 & 2.00 & 1.40 & 1.41 & 1.41 \\
\hline $\mathrm{CP}$ - variable 3 & 2.13 & 2.13 & 2.13 & 2.03 & 2.03 & 2.03 & 1.05 & 1.05 & 1.05 \\
\hline $\mathrm{CPk}$ - variable 1 & 2.33 & 0.33 & 0.33 & 2.02 & 0.29 & 0.29 & 1.15 & 1.14 & 1.14 \\
\hline $\mathrm{CPk}$ - variable 2 & 2.80 & 2.47 & 1.13 & 2.00 & 1.76 & 0.81 & 1.40 & 1.40 & 1.40 \\
\hline $\mathrm{CPk}$ - variable 3 & 2.13 & 2.13 & 0.8 & 2.03 & 2.04 & 0.76 & 1.05 & 1.04 & 1.05 \\
\hline CP (Veevers) & 1.25 & 1.24 & 1.24 & 1.15 & 1.15 & 1.15 & 1.09 & 1.08 & 1.08 \\
\hline CPk (Veevers) & 1.25 & 0.33 & 0.27 & 1.15 & 0.29 & 0.18 & 1.09 & 1.14 & 1.50 \\
\hline $\mathrm{CP}$ (geometric) & 2.41 & 2.41 & 2.41 & 2.02 & 2.02 & 2.02 & 1.19 & 1.19 & 1.19 \\
\hline CPk (geometric) & 2.41 & 1.21 & 0.67 & 2.02 & 1.01 & 0.56 & 1.19 & 1.20 & 1.20 \\
\hline CP (Niverthi-Dey) & 1.33 & 1.33 & 1.33 & 1.17 & 1.18 & 1.17 & 1.14 & 1.13 & 1.14 \\
\hline CPk (Niverti-Dey) & 1.33 & -1.41 & -0.30 & 1.17 & -1.14 & -0.23 & 1.14 & 1.24 & 1.30 \\
\hline $\begin{array}{c}\text { Cpm } \\
\text { (Mingoti-Glória) }\end{array}$ & 2.10 & 2.03 & 2.03 & 1.91 & 1.97 & 1.97 & 1.10 & 1.03 & 1.03 \\
\hline $\begin{array}{c}\text { Cpkm } \\
\text { (Mingoti-Glória) }\end{array}$ & 2.10 & 0.32 & 0.32 & 1.91 & 0.28 & 0.28 & 1.10 & 1.14 & 1.14 \\
\hline
\end{tabular}


Table 6. Capability indices results - VARMA $(1,1)-\mathrm{p}=2$.

\begin{tabular}{|c|c|c|c|c|c|c|c|c|c|}
\hline \multirow{2}{*}{ Capability index } & \multicolumn{3}{|c|}{ By matrix $\Sigma$ cases } & \multicolumn{3}{c|}{ By matrix $\Gamma(0)$ cases } & \multicolumn{3}{c|}{$\begin{array}{c}\text { Ratio } \\
\text { between indices }\end{array}$} \\
\hline & 5 & 6 & 7 & 5 & 6 & 7 & 5 & 6 & 7 \\
\hline CP - variable 1 & 2.22 & 2.22 & 2.22 & 2.01 & 2.01 & 2.01 & 1.10 & 1.10 & 1.10 \\
\hline CP - variable 2 & 2.00 & 0.33 & 2.00 & 2.00 & 0.33 & 2.00 & 1.00 & 1.00 & 1.00 \\
\hline CPk - variable 1 & 2.20 & 2.22 & 0.86 & 2.00 & 2.00 & 0.79 & 1.10 & 1.11 & 1.09 \\
\hline CPk - variable 2 & 2.00 & 0.33 & 0.66 & 2.00 & 0.33 & 0.66 & 1.00 & 1.00 & 1.00 \\
\hline CP (Veevers) & 1.38 & 0.33 & 1.38 & 1.33 & 0.33 & 1.34 & 1.04 & 1.00 & 1.03 \\
\hline CPk (Veevers) & 1.38 & 0.33 & 0.58 & 1.33 & 0.33 & 0.52 & 1.04 & 1.00 & 1.12 \\
\hline CP (geometric) & 2.10 & 0.86 & 2.10 & 2.00 & 0.82 & 2.00 & 1.05 & 1.05 & 1.05 \\
\hline CPk (geometric) & 2.10 & 0.86 & 0.76 & 2.00 & 0.82 & 0.72 & 1.05 & 1.05 & 1.06 \\
\hline CP (Niverthi-Dey) & 1.57 & -0.29 & 1.57 & 1.63 & -0.19 & 1.63 & 0.96 & 1.53 & 0.96 \\
\hline CPk (Niverti-Dey) & 1.57 & -0.29 & 0.48 & 1.63 & -0.18 & 0.51 & 0.96 & 1.61 & 0.94 \\
\hline Cpm (Mingoti-Glória) & 2.04 & 0.34 & 2.04 & 2.02 & 0.34 & 2.02 & 1.01 & 1.00 & 1.01 \\
\hline Cpkm (Mingoti-Glória) & 2.04 & 0.34 & 0.68 & 2.02 & 0.34 & 0.67 & 1.01 & 1.00 & 1.01 \\
\hline
\end{tabular}

$$
\begin{aligned}
& \widehat{\Phi}=\left(\begin{array}{rr}
0.6501 & -0.0089 \\
0.0017 & 0.7467
\end{array}\right) ; \hat{\Sigma}=\left(\begin{array}{rr}
0.0325 & -0.0135 \\
-0.0135 & 0.0110
\end{array}\right) \\
& \widehat{\Gamma}_{0}=\left(\begin{array}{rr}
0.0568 & -0.0264 \\
-0.0264 & 0.0247
\end{array}\right) ; \hat{p}(0)=\left(\begin{array}{rr}
1 & -0.669 \\
-0.669 & 1
\end{array}\right)
\end{aligned}
$$

$$
\begin{aligned}
& \widehat{\Phi}=\left(\begin{array}{ll}
0.6525 & 0.0000 \\
0.0000 & 0.7428
\end{array}\right) ; \hat{\mu}_{0}=(21.1618 ; 6.1597) ; \\
& \widehat{\Sigma}=\left(\begin{array}{lr}
0.0322 & -0.0134 \\
-0.0134 & 0.0109
\end{array}\right) \widehat{\Gamma}_{0}=\left(\begin{array}{cr}
0.0561 & -0.0260 \\
-0.0260 & 0.0244
\end{array}\right) ; \hat{\rho}(0)=\left(\begin{array}{cc}
1 & -0.680 \\
-0.680 & 1
\end{array}\right)
\end{aligned}
$$

where $\hat{\rho}(0)$ is the estimated correlation matrix based on $\hat{\Gamma}_{0}$ and $\hat{\mu}_{0}$ is the process vector mean estimate. For a confidence level of $99.73 \%$ (i.e. $\alpha=0.0027$ ) the constant $m$ is 3 and $C_{r \alpha}$ is 3.014. The capability estimates are shown in Table 7. As one can see the non-capability condition of the process is signaled by the $C_{p k}$ univariate indices as well as by their geometric means. Among the other multivariate capability indices Veevers' and Mingoti and Glória's were more sensitive to the non-capability condition of the process. On the contrary, Niverthi and Dey's indices were not able to signal the noncapability given numerical values larger than 1 .

The bootstrap methodology (Efron and Tibashirani, 1993) was used to generate confidence intervals for the true process capability indices for each 


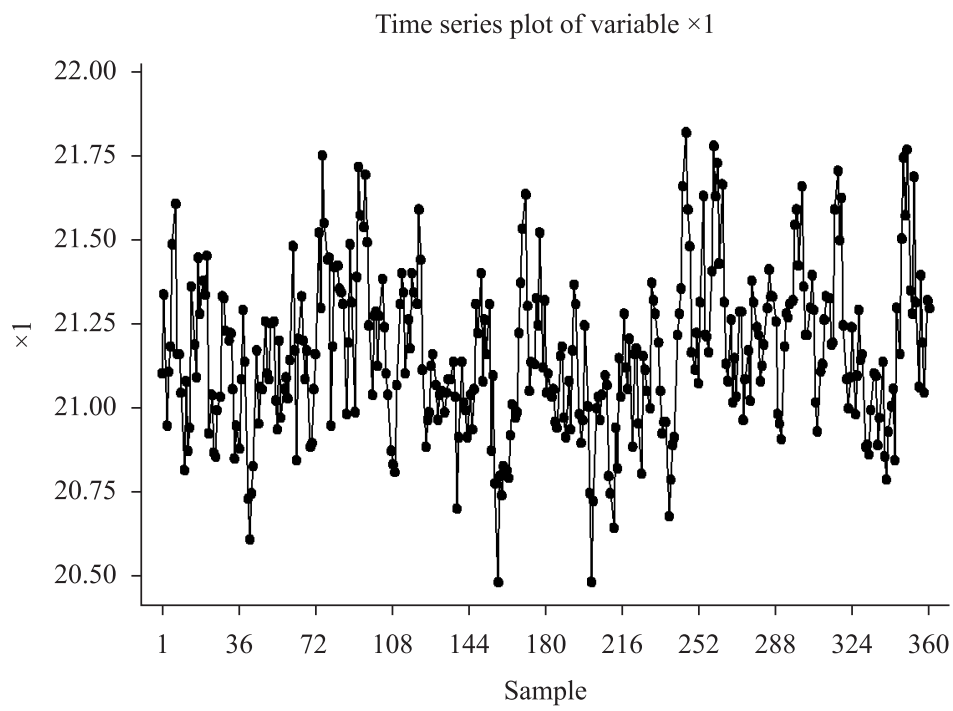

Time series plot of variable $\times 2$

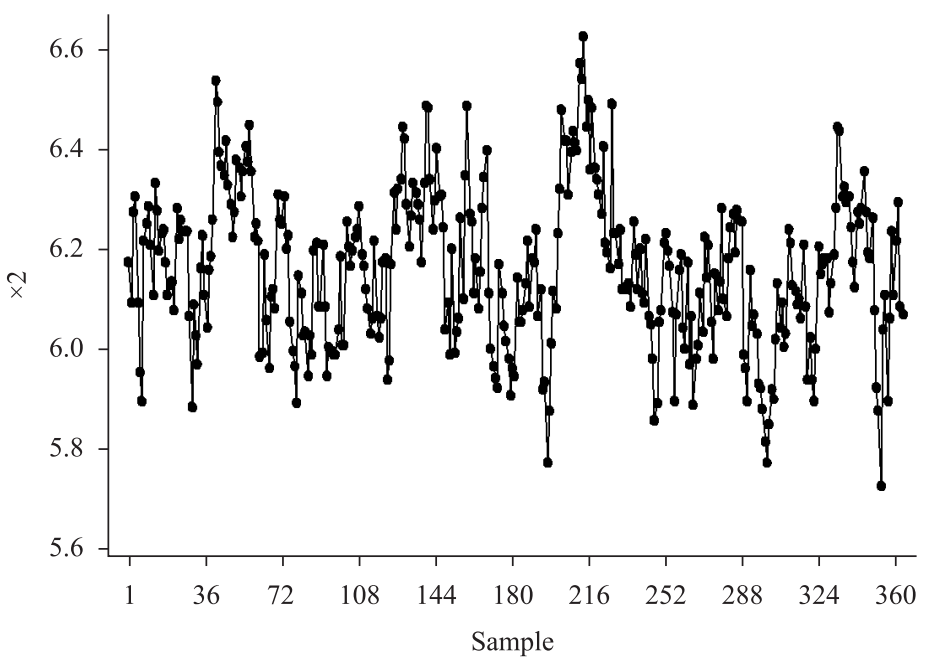

Figure 2. Series of observations of both variables - the blast charcoal furnace of pig iron production.

methodology. A total of $m=1000$ bootstrap samples of sizes $n=360$ were selected with replacement. For each bootstrap sample the estimates of all multivariate capability indices discussed in this paper were calculated at $\alpha=0.0027$ and compared to the corresponding bootstrap values of Table 7 . The mean error $(M E)$, the absolute mean error $(A M E)$ and the squared mean error $(S M E)$ were calculated (see Table 7 for the results). As we can see the $M E, A M E$ and the $S M E$ values were larger for Niverthi and Dey estimates than for Mingoti and Glória, the geometric means and Veevers indices. All indices are practically unbiased (mean errors close to zero) and their distributions 
Partial autocorrelation function for $\times 1$

(with 5\% significance limits for the partial autocorrelations)

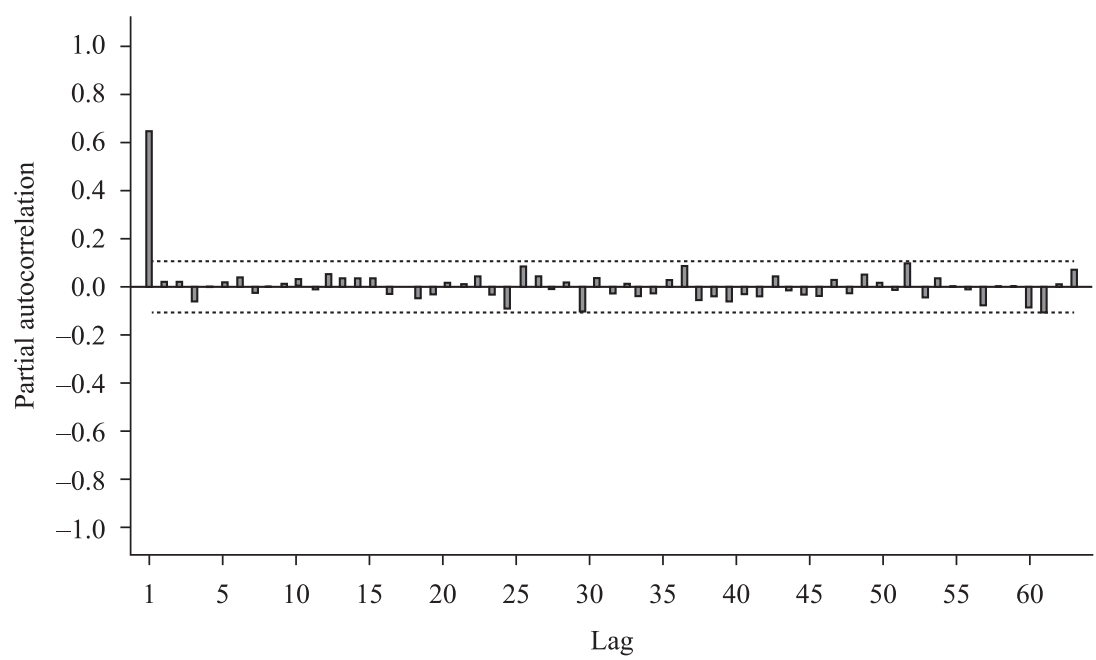

Partial autocorrelation function for $\times 2$

(with $5 \%$ significance limits for the partial autocorrelations)

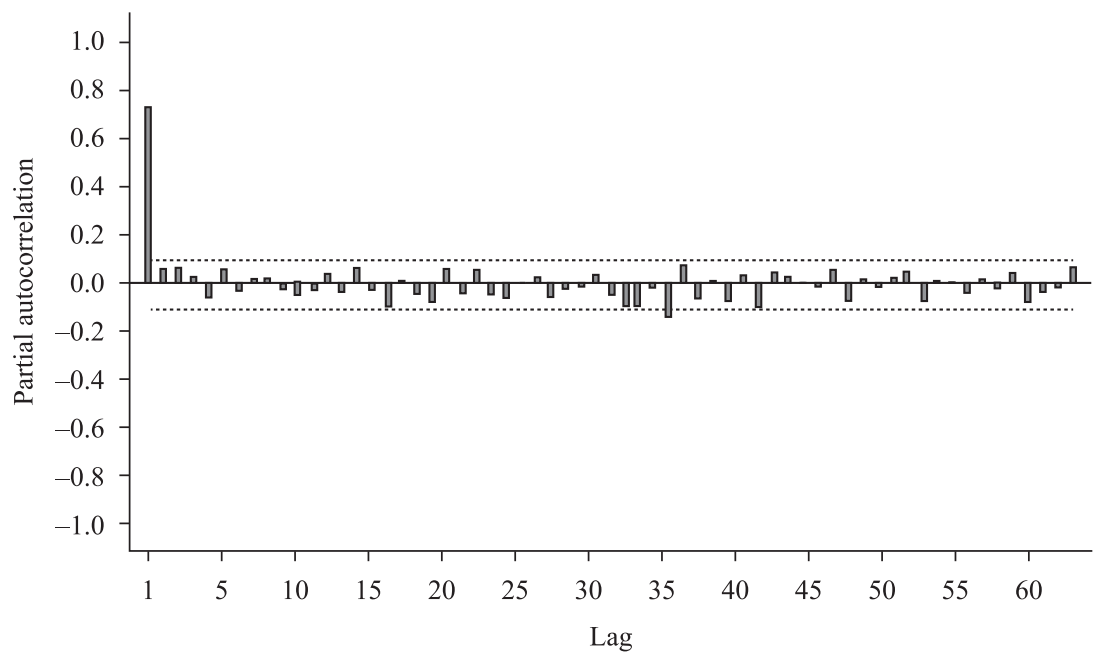

Figure 3. Partial autocorrelation of the blast charcoal furnace of pig iron production series.

resemble the univarite normal except Veevers $C_{p}$ (Figure 4). For all multivariate indices, except Niverthi and Dey, the $95 \%$ bootstrap confidence limits for the true capability show that the process is non-capable since the upper limit is lower or very close to 1. The lower limits of the confidence interval built using Niverthi and Dey's indices were very far from 1 giving no sign at all of the non-capability of the process. The confidence interval using Mingoti and Glória's, $\mathrm{C}_{p k}^{m}$, resulted in smaller range (0.139) than Niverthi and Dey's, $C_{p k N D}(0.262)$ and Veeevers' $C_{p k m u l t i}(0.171)$. 

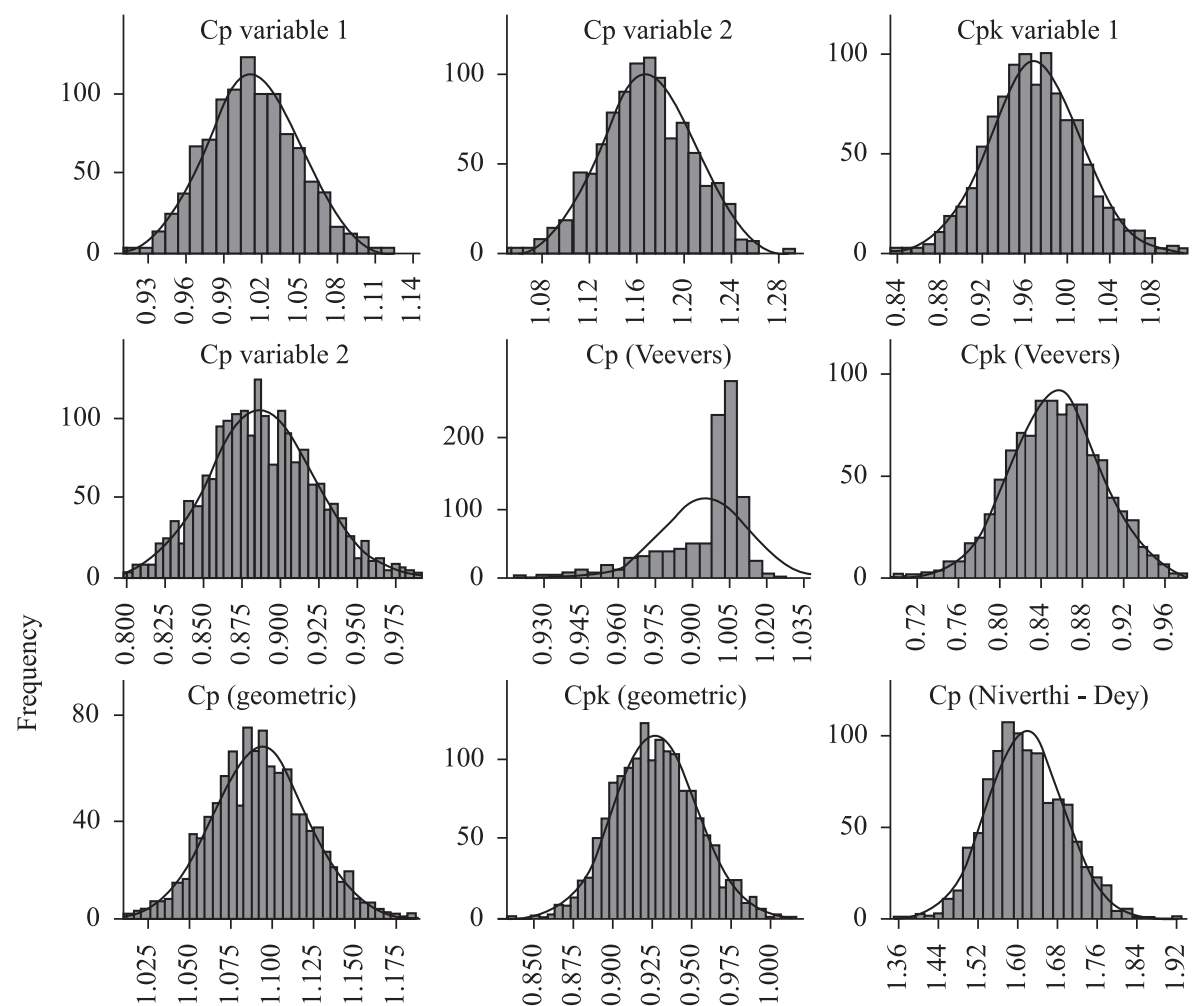

กิ
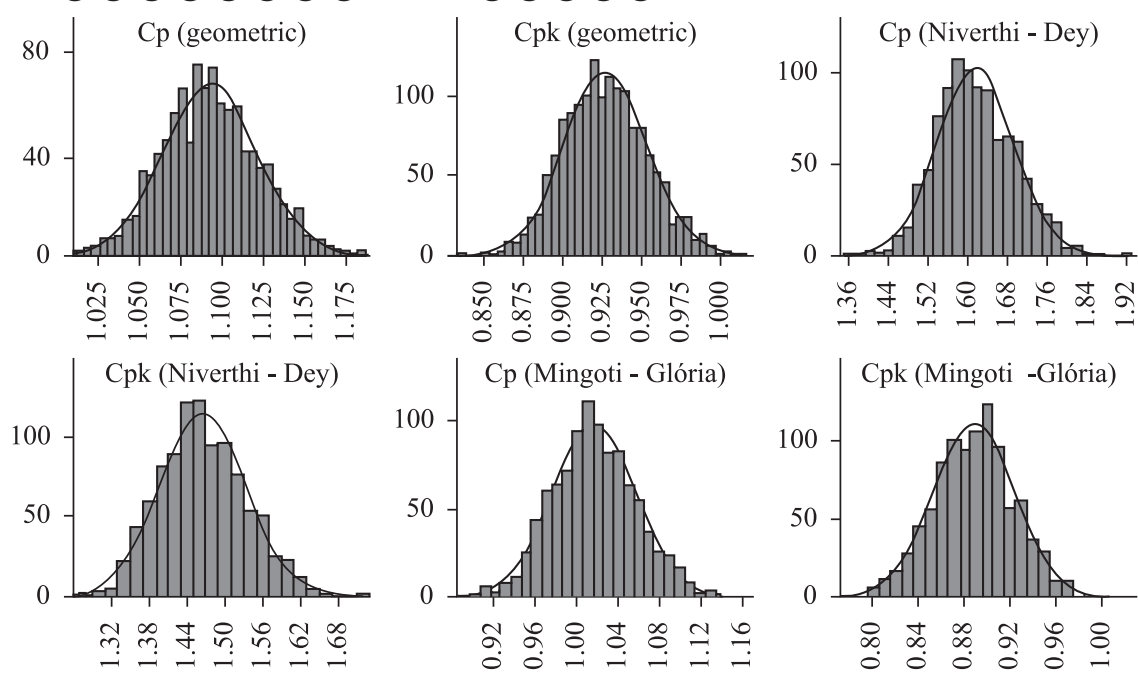

Figure 4. Histograms from the capability bootstrap estimates.

\section{Final Remarks}

This paper shows the importance of taking into account the autocorrelation of the process in the calculation of capability multivariate indices. As we have shown, in the presence of autocorrelation a non-capable process may be considered capable if the capability index is not properly corrected. In a real situation the user needs to collect enough data to correctly identify the multivariate time series model which had generated the observations of the process. For a VAR(1) model the routine mAr.est from the software $R$ for windows may be used to estimate the matrices $\Phi_{p x p}, \Sigma_{p x p}, \Gamma(0)$ and $\rho(0)$. The estimation procedure is based upon a minimum squares stepwise (Neumaier and Schneider, 2001). The user can also make its own program to obtain a maximum likelihood solution (Lutkepohl, 2005). By doing so any capability multivariate index 
Table 7. Estimate capability and bootstrap results for the blast charcoal furnace example.

\begin{tabular}{|c|c|c|c|c|c|c|}
\hline $\begin{array}{c}\text { Capability } \\
\text { Indices }\end{array}$ & Estimate $\left(^{*}\right)$ & $\begin{array}{c}\text { Bootstrap } \\
\text { estimate }\end{array}$ & $\begin{array}{c}\text { Bootstrap 95\% } \\
\text { confidence interval }\end{array}$ & $E M$ & AEM & $S M E$ \\
\hline $\begin{array}{c}\text { Cp - } \\
\text { variable } 1\end{array}$ & 1.013647 & 1.008772 & $\begin{array}{c}(0.946561 ; \\
1.087939)\end{array}$ & -0.0049 & 0.0289 & 0.0013 \\
\hline $\begin{array}{c}\text { Cp - } \\
\text { variable } 2\end{array}$ & 1.168415 & 1.193694 & $\begin{array}{c}(1.092717 ; \\
1.242791)\end{array}$ & 0.0253 & 0.0381 & 0.0022 \\
\hline $\begin{array}{c}\text { Cpk - } \\
\text { variable 1 }\end{array}$ & 0.969903 & 0.964912 & $\begin{array}{c}(0.891059 ; \\
1.058655)\end{array}$ & 0.0778 & 0.0781 & 0.0072 \\
\hline $\begin{array}{c}\text { Cpk - } \\
\text { variable } 2\end{array}$ & 0.887130 & 0.900900 & $\begin{array}{c}(0.822696 ; \\
0.955191)\end{array}$ & 0.0138 & 0.0299 & 0.0014 \\
\hline $\begin{array}{c}\text { Cp } \\
\text { (Veevers) }\end{array}$ & 0.994767 & 1.001413 & $\begin{array}{c}(0.946561 ; \\
1.013515)\end{array}$ & 0.0066 & 0.0114 & 0.0003 \\
\hline $\begin{array}{c}\text { Cpk } \\
\text { (Veevers) }\end{array}$ & 0.855012 & 0.869290 & $\begin{array}{c}(0.770196 ; \\
0.940605)\end{array}$ & 0.0143 & 0.0374 & 0.0021 \\
\hline $\begin{array}{c}\text { Cp } \\
\text { (geometric) }\end{array}$ & 1.088044 & 1.097344 & $\begin{array}{c}(1.033706 ; \\
1.147314)\end{array}$ & 0.0093 & 0.0254 & 0.0010 \\
\hline $\begin{array}{c}\text { CpK } \\
\text { (geometric) }\end{array}$ & 0.927210 & 0.932357 & $\begin{array}{c}(0.877608 ; \\
0.982263)\end{array}$ & 0.0051 & 0.0221 & 0.0008 \\
\hline $\begin{array}{c}\text { Cp } \\
\text { (Niverthi-Dey) }\end{array}$ & 1.617019 & 1.700645 & $\begin{array}{c}(1.484890 ; \\
1.774682)\end{array}$ & 0.0836 & 0.0961 & 0.0129 \\
\hline $\begin{array}{c}\text { CpK } \\
\text { (Niverti-Dey) }\end{array}$ & 1.465741 & 1.532651 & $\begin{array}{c}(1.345717 ; \\
1.607757)\end{array}$ & 0.0669 & 0.0810 & 0.0093 \\
\hline $\begin{array}{c}\text { Cp } \\
\text { (Mingoti-Glória) }\end{array}$ & 1.016766 & 1.041212 & $\begin{array}{c}(0.940826 ; \\
1.098406)\end{array}$ & 0.0244 & 0.0389 & 0.0023 \\
\hline $\begin{array}{c}\text { Cpk } \\
\text { (Mingoti-Glória) }\end{array}$ & 0.888364 & 0.927983 & $\begin{array}{c}(0.819098 ; \\
0.958860)\end{array}$ & 0.0396 & 0.0446 & 0.0028 \\
\hline
\end{tabular}

*The estimate is obtained by using the original data (sample size $\mathrm{n}=360$ ).

discussed in this paper can be calculated. Confidence intervals for the true capability index can also be built by using the bootstrap methodology as an alternative.

The results of this paper had shown that Veever's and Mingoti and Glória's multivariate capability indices performed better than Niverthi and Dey's and were less subject to wrong conclusions about the capability or non-capability of the process. Since they are even easier to calculate they should be preferred.

Finally, in this paper for $\operatorname{VAR}(1)$ and $p=2$ it was presented the correspondence between the capability index value and the probability (p) of non-conforming units generated by the process according to the specification limits. As a future work it would be interesting to establish some reference values for the multivariate indices to be used to classify the process capability in bands similar as done for univariate processes. 


\section{Acknowledgments}

The authors were partially supported by the Brazilian institutions: CAPESHigh Level Staff Improvement Coordination and CNPq- National Council for Scientific and Technological Development.

\section{References}

Alwan, L.C. and Roberts, H.V. (1995) The Problem of Misplaced Control Limits. Applied Statistics, Vol. 44, No. 3, pp. 269-278. http://dx.doi.org/10.2307/2986036

Bernardo, J.M. and Irony, T.X. (1996) A General Multivariate Bayesian Process Capability Index. Statistician, Vol. 45, pp. 487-502. http://dx.doi.org/10.2307/2988547

Chan, L.K.; Chen, S.W. and Spiring, F.A. (1991) A Multivariate Measure of Process Capability. International. Journal of Modeling and Simulation, Vol. 11, No. 1, pp. 1-6.

Chen, H. (1994) A Multivariate Process Capability Index Over a Rectangular Solid Tolerance Zone. Statistica Sinica, Vol. 4, No. 2, pp.749-758.

Cheng, S.W. and Spiring, F.A. (1989) Assessing Process Capability: A Bayesian Approach. IIE Transactions, Vol. 21, pp. 97-98. http://dx.doi.org/10.1080/07408178908966212

Efron, B. and Tibshirani, R.J. (1993) An Introduction to the Bootstrap. New York: Chapman and Hall.

Hayter, A.J. and Tsui, K-L. (1994) Identification and Quantification in Multivariate Quality Control Problems. Journal of Quality Technology, Vol. 26, No. 3, pp.197-208.

Hotelling, H. (1947), Multivariate quality control, in: Eisenhart, M.; Hastay, W. and Wallis, A. (Eds.), Techniques of Statistical Analysis. New York: MacGraw-Hill, pp. 111-184.

Jarret, J. and Pan, X. (2007) The Quality Control Chart for Monitoring Multivariate Autocorrelated Processes. Computational Statistics and Data Analysis, Vol. 51, No. 8, pp. 38623870. http://dx.doi.org/10.1016/j.csda.2006.01.020

Kalgonda, A.A. and Kulkarni, S.R. (2004) Multivariate Quality Control Chart for Autocorrelated Processes. Journal of Applied Statistics, Vol. 31, No. 3, pp.317-327. http://dx.doi. org/10.1080/0266476042000184000

Koltz, S. and Johnson, N.L. (2002) Process Capability Indices-A Review. 1992-2000. Journal of Quality Technology, Vol. 34, No. 1, pp. 2-39.

Koltz, S. and Johnson, N.L. (1993), Process Capability Indices. London: Chapman and Hall.

Kramer, H.G. and Schmid, W. (1997) EWMA Charts for Multivariate Time Series. Sequential Analysis, Vol. 16, No. 2, pp. 131-154. http://dx.doi.org/10.1080/07474949708836378 Verlag.

Lutkepohl, H. (2005), Introduction to Multiple Time Series Analysis. Berlin: Springer

Mason, R.L. and Young, J.C. (2002) Multivariate Statistical Process Control with Industrial Applications. Alexandria: American Statistics Society. http://dx.doi. org/10.1137/1.9780898718461

Mingoti, S.A. and Glória, F.A.A. (2008) Comparing Mingoti and Glória's and Niverthi and Dey's Multivariate Capability Indices. Produção, Vol. 18, No. 3, pp. 598-608. http:// dx.doi.org/10.1590/S0103-65132008000300014

Neumaier, A. and Schneider, T. (2001) Estimation of Parameters and Eigenmodes of Multivariate Autoregressive Models. ACM Transactions on Mathematical Software, Vol. 27, No.1, pp.27-57. http://dx.doi.org/10.1145/382043.382304 
Niverthi, M. and Dey, D.K. (2000) Multivariate Process Capability: A Bayesian Perspective. Communications in Statistics-Simulation and Computation, Vol. 29, No. 2, pp.667687. http://dx.doi.org/10.1080/03610910008813634

Pearn, W.L.; Wang, F.K. and Yen, C.H. (2007) Multivariate Capability Indices: Distributional and Inferential Properties. Journal of Applied Statistics, Vol. 34, No. 8, pp. 941962. http://dx.doi.org/10.1080/02664760701590475

Shahriari, H.; Hubele, N.F. and Lawrence, F.P. (1995) A Multivariate Process Capability Vector, in: Industrial Engineering Research Conference, Institute of Industrial Engineers, pp. 304-309.

Taam, W.; Subbaiha, P. and Liddy, J.W. (1993) A Note on Multivariate Capability Indices. Journal of Applied Statistics, Vol. 20, No. 3, pp.339-351. http://dx.doi. org/10.1080/02664769300000035

Veevers, A. (1998) Viability and Capability Indices for Multiresponse Processes. Journal of Applied Statistics, Vol. 25, No. 4, pp.545-558. http://dx.doi.org/10.1080/02664769823016

Wang, F.K.; Hubele, N.F.; Lawrence, F.P.; Miskulin, J.O. and Shariari, H. (2000) Comparison of three Multivariate Process Capability Indices. Journal of Quality Technology, Vol. 32, No. 3, pp. 263-275.

Zhang, N.Z. (1998) Estimating Process Capability Indices for Autocorrelated Data. Journal of Applied Statistics, Vol. 25, No. 4, pp.559-574. http://dx.doi.org/10.1080/02664769823025

\section{Biography}

Sueli Aparecida Mingoti is an Associate Professor at the Statistics Departament of Federal University of Minas Gerais (UFMG),Brazil. She received her $\mathrm{Ph} . \mathrm{D}$ degree in Statistics from the Iowa State University located at Ames, United States of America, in 1989. Her research interests includes applied probability and inference, multivariate and industrial statistics.

Contact: sueliam@est.ufmg.br

Fernando Luiz Pereira de Oliveira received his D.Sc. from the Department of Statistics at Federal University of Minas Gerais, in 2011. Since then he has been serving on the Department of Mathematics at Federal University of Ouro Preto (UFOP), Minas Gerais, Brazil. His major interests are process capability, statistical quality control and clusters detection.

Contact: fernandoluiz@iceb.ufop.br

\section{Article Info:}

Received: May, 2010

Accepted: June, 2011 
